\title{
Comparison of Unilateral versus Bilateral Pedicle Screw Fixation in Transforaminal Lumbar Interbody Fusion for Single Level Lumbar Degenerative Diseases and Review of Literature
}

\author{
Hasan Serdar ISIK', Ozerk OKUTAN², Timur YILDIRIM¹', Elif AKPINAR², Ali YILMAZ \\ ${ }^{1}$ Ordu University, School of Medicine, Department of Neurosurgery, Ordu, Turkey \\ ${ }^{2}$ KTO Karatay University, School of Medicine, Department of Neurosurgery, Konya, Turkey \\ This study has been presented at the $31^{\text {st }}$ Scientific Congress of Turkish Neurosurgical Society, March 29 - April 2, 2017 in Antalya, Turkey
}

\section{ABSTRACT}

AIM: To examine the clinical and radiological follow-ups and results of the patients undergoing fusion procedure by unilateral versus bilateral pedicle screw fixation (PSF) along with transforaminal lumbar interbody fusion (TLIF).

MATERIAL and METHODS: Fifty-four patients were included in the study. Thirty-three patients were operated with bilateral PSF and TLIF and 21 had unilateral PSF and TLIF. The patients were evaluated preoperatively, on the postoperative $15^{\text {th }}$ day, $6^{\text {th }}$ and $12^{\text {th }}$ months, and at the time of last examination (38 months in average for all patients) using Visual Analogue Scale (VAS) and Oswestry Disability Index (ODI). Fusion rates were examined with direct X-rays with flexion-extension dynamic views and 3D computed tomography (CT) scans.

RESULTS: Operation times were shorter and blood loss was less in the unilateral PSF group. Fusion rates were similar in both groups with no statistical significance. For both groups, significant clinical improvement was observed based on the preoperative and postoperative scores.

CONCLUSION: Unilateral PSF along with TLIF procedure is an effective option in selected patients. We need prospective randomized studies with higher number of patients and longer follow-up periods for more reliable results.

KEYWORDS: Bilateral fixation, Interbody fusion, Lumbar degenerative disc disease, Unilateral fixation

\section{INTRODUCTION}

$\mathrm{F}$ Tor the last couple of decades particularly, both the increase in average age throughout the world and the developments in diagnostic technologies have gradually increased the importance of lumbar degenerative diseases in the practice of neurosurgery. The most widely accepted algorithm in the literature is medical treatment for an appropriate period of time, physical therapy and minimally invasive pain-relieving therapies, if necessary, followed by surgical interventions. The most common surgical intervention is the decompression of neural elements followed by pedicle screw fixation (PSF) for fusion. Together with the definition of transforaminal lumbar interbody fusion (TLIF) by Harms, particularly after 1990s, TLIF procedures are added to the pedicle screw practices, and many authors in the literature reported that a more strong and reliable fusion could be possible with this technique $(10,12)$.

In recent years, there is an ongoing discussion in the literature on whether the pedicle screw fixation implemented together with TLIF in order to have a more strong, reliable, less invasive, less expensive fusion with less complications, should be implemented unilaterally or bilaterally $(2,19)$. In 
fact, traditionally practiced bilateral PSF and instrumentation performed together with TLIF can be regarded as a convenient procedure for a reliable, effective and biomechanically sufficient fusion $(6,12,18,21)$. On the other hand, it is reported that extreme rigidity caused by bilateral screw fixation lead to development of adjacent segment disease (ASD). Subsidence of bone graft and decline in bone mineral cause a decrease in fusion rates. $(6,12,18,25,39-41)$. Likewise, it is reported in the literature that unilateral pedicle fixation with the TLIF procedure has many advantages compared to bilateral PSF. The main advantages are shorter operation time, less invasive surgical procedure, less blood loss, less postoperative pain, shorter hospital stay, less cost and less co-morbidities of ASD $(5,14,16,18,28,44)$. Nonetheless, some researchers state that unilateral screw fixation decreases stability and rigidity related to the axial rotational resistance and lateral bending, which is seen together with less fusion, leading to more cage migration cases and that it is not suitable for the stabilization of long segments $(11-13,21,23,33,35,36,40,42)$. Therefore, it is obvious that a consensus is yet to be reached in the literature as regards which instrumentation should be used on which patient and how.

In this study, we examined the clinical and radiological followup and results of our patients undergoing fusion procedure by unilateral versus bilateral PSF along with TLIF. We aimed at contributing to the discussions in the literature by analyzing the results together with previously published studies.

\section{- MATERIAL and METHODS}

The approval of the Ethics Committee for Clinical Studies of Ordu University was received for this retrospective study with the decision numbered 2017/33.

\section{Patient Selection}

For the purpose of this study, 54 of the 76 patients who were operated at our clinics with TLIF and unilateral PSF or bilateral PSF due to single level lumbar degenerative disc disease between January 2011 and January 2016 were scanned.

Inclusion criteria were;

1. Cases where single level fusion was performed,

2. TLIF implemented cases,

3. Cases followed up for at least 12 months.

Exclusion criteria were;

1. Cases where fusion of more than a single level was performed,

2. Cases without TLIF,

3. Cases that were treated with single level fusion because of deformity, tumor or trauma,

4. Cases with other serious systemic diseases (such as; severe osteoporosis, metabolic or vascular diseases, infection),

5. Cases that were lost during follow-up before 12 months due to any reason whatsoever,
6. Cases with past history of lumbar fusion surgery,

\section{Cases with more than Grade 1 spondylolisthesis}

As a result of the assessment, 54 patients were included in the study. All patients had severe low back pain, leg pain, and neurological symptoms at various levels. Each and every patient was first treated with medical methods such as rest, medical treatment and physical therapy for appropriate periods. For those, who did not benefit from medical treatment, surgery was decided upon analyzing direct graphs, lumbar magnetic resonance imaging (MRI) and computed tomography (CT) results and exam findings.

A total of 33 patients were operated with bilateral PSF and TLIF and 21 had unilateral PSF and TLIF. Both groups of patients were analyzed according to their demographic data such as age, gender, follow-up period, diagnosis, and levels of operation. Furthermore, information regarding operation time, amount of intraoperative bleeding, and duration of hospital stay of all the patients were also retrieved from the files and recorded. In terms of peroperative and early postoperative complications, on the other hand, dural injury, screw malposition, infection and thromboembolism were evaluated and for long term follow-ups, information related to screw failure, cage migration, fusion and adjacent segment disease were recorded.

Regarding functionality, the patients were evaluated preoperatively, on the postoperative $15^{\text {th }}$ day, $6^{\text {th }}$ month and $12^{\text {th }}$ month, and at the time of last examination (38 months in average for all patients) using Visual Analogue Scale (VAS) and Oswestry Disability Index (ODI). In addition to functional assessment, the patients, who were also followed up radiologically, were evaluated in terms of their fusion rates at the surgical site. For this assessment, all patients had direct lateral $\mathrm{X}$-ray films with flexion-extension dynamic views and three-dimensional CT scan as a routine radiological imaging in our clinic for spinal stabilization patients. In order to report a fusion as suitable, less than 4 degrees of angular motion on flexion-extension views between the fused segments and bone bridging the disc space without lucency had to be met as a condition $(38,39,41)$.

\section{Surgical Procedure}

Following the necessary and routine preoperative preparations, all patients were taken into operation in prone position under general endotracheal anesthesia. After the level was identified under the guidance of $\mathrm{C}$-arm fluoroscopy, the operations were started with a skin incision of $4 \mathrm{~cm}$ in the unilateral group, as opposed to 6-7 cm in the bilateral group. The paravertebral muscles were retracted to the lateral at the symptomatic side in the unilateral group and at both sides in the bilateral. Then, decompression was performed for the existing and transversing roots and neural elements by means of hemipartial laminectomy, flavectomy and facetectomy in the unilateral group, as opposed to total laminectomy, bilateral flavectomy and bilateral facetectomy in the bilateral. The bones removed during laminectomy and facetectomy were kept to be used as autografts. After that, pedicle screws were inserted unilaterally (Figure $1 \mathrm{~A}-\mathrm{C}$ ) and bilaterally under the 
guidance of C-arm fluoroscopy (Figure 2A, B). Discectomy followed this procedure and a cage filled with bone particles was placed in the disc space. All the operations were performed by the same two experienced neurosurgeons at both centers. All patients were evaluated with direct radiographs and CT scans on the postoperative $1^{\text {st }}$ day and mobilized.

\section{Statistical Analysis}

All statistical analysis was performed by means of SPSS 17.0 for Windows software (SPSS Inc., Chicago, IL, USA). First, the data (demographic data, operation time, blood loss, hospital stay, rate of fusion, complications etc) were analysed using Levene's test and the Shapiro-Wilk test for equality of variance and normality assumption, both at $p>0.05$, respectively except for VAS scores. So, Student t-test were secondly applied to determine whether there were differences between the implemented procedures (Unilateral and Bilateral
Pedicle Screw Fixation) for ages, operation time, blood loss, hospital stay. Thirdly, chi-square test and Fisher's exact test were applied to determine whether there was a relationship between the implemented procedures and gender, diagnosis, level, complications, fusion rates, ASD. Finally, ODI (\%) scores recorded at certain times (preoperatively, postoperative $15^{\text {th }}$ day, $6^{\text {th }}$ month, $12^{\text {th }}$ month and the assessments at the last visit with an average of 38 months) were analyzed by means of one-way ANOVA with repeated measures while VAS scores recorded at certain times (preoperative, postoperative $15^{\text {th }}$ day, $6^{\text {th }}$ month, $12^{\text {th }}$ month and the assessments at the last visit with an average of 38 months) were analyzed by means of Friedman test. $\mathrm{p}$-value less than 0.05 was considered as statistically significant. According to this test results, the findings were expressed as a sample size, mean with standard deviation.
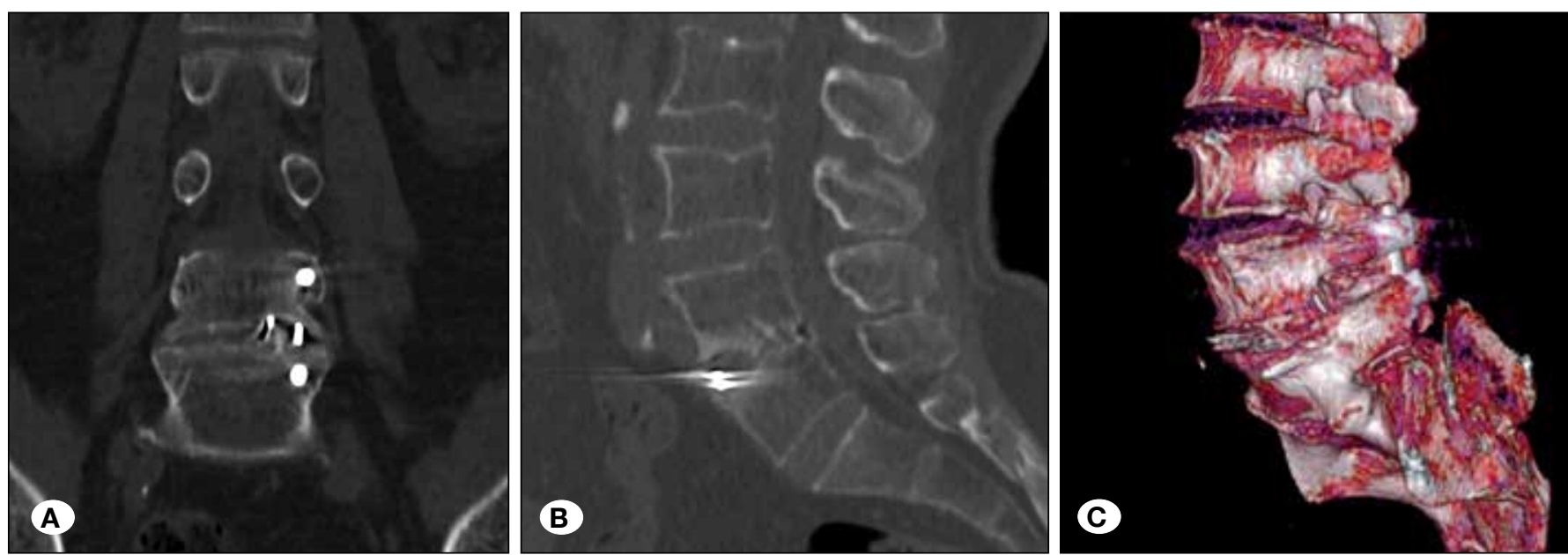

Figure 1: The coronal (A), sagittal (B), and 3D (C) CT reconstructions showing unilateral pedicle screw fixation and solid bony fusion.
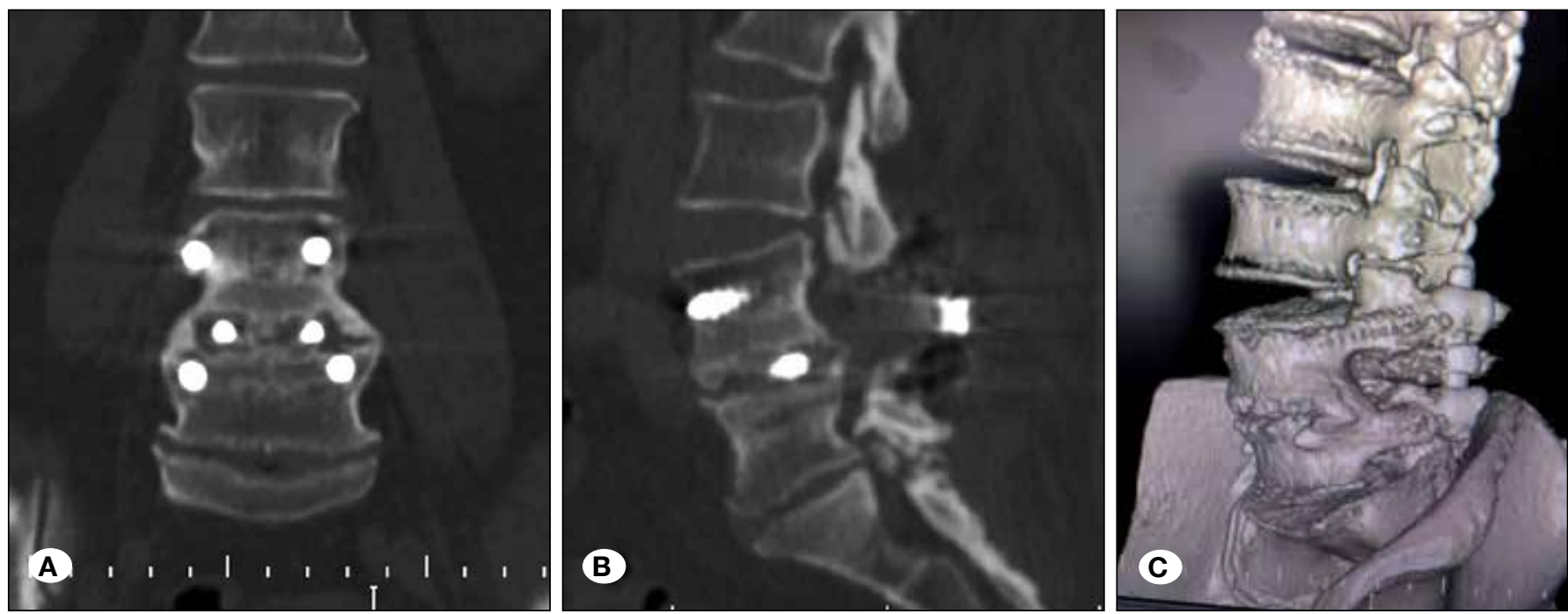

Figure 2: The coronal (A), sagittal (B), and 3D (C) CT reconstructions showing bilateral pedicle screw fixation and solid bony fusion. 


\section{RESULTS}

Ages, gender differences between the groups, follow-up periods, diagnoses and levels of surgery are summarized in Table I. There was no difference between the groups significant enough to be reported statistically. While the average followup period was 36 months in the unilateral PSF group, it was 39 months in the bilateral PSF group. This period of time was deemed appropriate and sufficient for the evaluation of the fusion and for the follow-up of the system-associated complications that may develop.

Operation times were shorter and blood loss was less in the unilateral PSF group compared with the bilateral PSF group, reaching statistical significance. In addition, hospital stay in the unilateral PSF group was significantly shorter than the bilateral PSF group. These results are summarized in Table II.

Fusion rates were similar in both groups with no statistical significance. Likewise, the rates of ASD were again similar in both groups. When we look at the complications, one case of superficial wound infection was reported for each group and both patients were treated with simple debridement and antibiotherapy, and discharged without any problems. No peroperative or early postoperative complications such as dural injury, cerebrospinal fluid (CSF) fistula, screw malposition, discitis, neural tissue damage and deep vein thrombosis were seen in any of the patients in our series. None of the patients had screw failure or cage migration in long-term follow-ups. Two patients in the unilateral PSF group and 3 in the bilateral PSF group had ASD. All patients diagnosed with ASD were those who were followed-up for 48 months or more. In our study, none of the patients needed re-operation during the follow-up period. The summary and statistics regarding fusion, ASD and complications are presented in Table III.

Functional assessment was done using VAS and ODI scores, and for both groups, statistically significant clinical improvement was observed in the preoperative and postoperative scores. When it comes to the comparison of the groups, however, no statistical difference was found in terms of clinical evaluation results. In other words, patients who had unilateral PSF and those who had bilateral PSF had similar recovery in clinical terms (Table IV).

\section{DISCUSSION}

The fusion procedure following neural decompression used in the surgical treatment of lumbar degenerative diseases is currently one the most common procedures in the practice of neurosurgery. The purpose of the fusion procedure is to ensure stability in unstable spinal segments, to provide the necessary disc elevation and to ensure load sharing with anterior elements $(5,18,23,44)$. For fusion, TLIF procedure defined by Harms along with the standard procedure of pedicle screw fixation, has become popular in the practice of neurosurgery and is a recognized practice in the literature for a sufficient and safe fusion $(10,16,39)$. It can be used as a convenient method for fusion particularly in Grade 1 and 2 spondylolisthesis cases, discogenic degenerative disc disease, recurrent lumbar disc herniation cases accompanied by radiculopathy or mechanical low back pain, in the treatment of pseudoarthrosis, lumbar spinal stenosis and deformity cases $(9,21,40)$. Many advantages of this procedure can be listed such as; safe implementation, the ability to perform both posterior and anterior fusion with posterior intervention, a broad solid fusion area under the pressure of upper and lower endplates, contribution to the improvement of disc elevation etc. $(12,28,33)$. In our study, all patients were operated with TLIF procedure and reported fusion rates were appropriate (Figure 1A-C).

Bilateral pedicle screw fixation is a standard procedure employed in lumbar degenerative diseases requiring fusion $(6,12,17,21,26,27)$. With this procedure, the necessary biomechanical stability is achieved and the clinical benefit of rigid fixation is sufficient and suitable $(5,18)$. Nevertheless, particularly in studies with long-term follow-up, it is reported that the fusion rate declines and the possibility of developing pseudoarthrosis is higher, the risk of osteoporosis is elevated as a result of the decline in bone mineral density and the risk of developing ASD becomes higher $(18,24,34,39,41)$. In 1991, Goel et al. defined the unilateral pedicle screw fixation procedure (9). Later on, many studies combining unilateral PSF with TLIF have been published up to now, and in a vast majority of these studies it is stated that it is possible to have a suitable and effective fusion. In series with short and medium term follow-up results, similar fusion rates are reported in unilateral PSF and bilateral PSF cases $(8,25,33,38)$. Likewise, in the systematic review published by Molinari et al., high and similar fusion rates are reported for both groups (23). On the other hand, in biomechanical studies investigating patients undergoing TLIF and unilateral PSF, it is stated that the procedure in question reduces rotational stability and rigidity, reducing the fusion rate. However, in an another study Ambati et al., showed higher biomechanical stability rates causing increased fusion construct stability and decreases posterior instrumentation stress in bilateral pedicular fixation in transforaminal lumbar interbody fusion $(1,11,35)$. In our study, unilateral cases were 2 and bilateral was 9 at L5-S1 level, which the pseudoarthrosis commonly occurs, and this difference may be a bias for unilateral group as a limitation of study. However in our study, when we analyze the average 36 month follow-up period for the unilateral PSF group and 39 months for the bilateral PSF group, similar fusion rates were achieved in both.

The number of levels that unilateral PSF should be implemented in order to achieve effective results is another debated topic in the literature. While researchers such as Yucesoy, Chen and Yang argue that it is more convenient to implement at single level, researchers such as Zhang, Mao and Xue reported favorable results also for 2 levels $(5,8,20,22,39,42,43,45)$. When the whole literature is checked, it can be seen that consensus is in favor of the single level implementation $(32,33,40)$. In this study, we included our single level TLIF and fusion cases and achieved statistically significant fusion results in line with the literature.

It is recognized that instrumentation is an important risk factor for all fusion cases in terms of adjacent segment disease 
Table I: Demographic Data

\begin{tabular}{|c|c|c|c|}
\hline Parameters & Unilateral & Bilateral & $\mathbf{p}$ \\
\hline Patients & 21 & 33 & \\
\hline Age (years) & $54.81 \pm 9.47$ & $56.00 \pm 11.43$ & 0.692 \\
\hline \multirow[t]{2}{*}{ Follow-up (months) } & $35.62 \pm 19.70$ & $39.45 \pm 10.20$ & 0.351 \\
\hline & n (\%) & n (\%) & \\
\hline \multicolumn{4}{|l|}{ Gender } \\
\hline Female & $11(52.4)$ & $19(57.6)$ & \multirow{2}{*}{0.708} \\
\hline Male & $10(47.6)$ & $14(42.4)$ & \\
\hline \multicolumn{4}{|l|}{ Diagnosis } \\
\hline LSS & $9(42.9)$ & $18(54.5)$ & \multirow{3}{*}{0.201} \\
\hline LSL & $1(4.8)$ & $5(15.2)$ & \\
\hline LDDD & $11(52.3)$ & $10(30.3)$ & \\
\hline \multicolumn{4}{|l|}{ Segments } \\
\hline $\mathrm{L} 2-3$ & $1(4.8)$ & $0(0.0)$ & \multirow{4}{*}{0.287} \\
\hline L3-4 & $2(9.5)$ & $4(12.1)$ & \\
\hline$\llcorner 4-5$ & $16(76.2)$ & $20(60.6)$ & \\
\hline L5-S1 & $2(9.5)$ & $9(27.3)$ & \\
\hline
\end{tabular}

LSS: Lumbar Spinal Stenosis, LSL: Lumbar Spondylolisthesis, LDDD: Lumbar Degenerative Disc Disease.

Table II: Clinical Results

\begin{tabular}{lccc}
\hline Parameters & Unilateral & Bilateral & $\mathbf{p}$ \\
\hline Operation time (minutes) & $111.7 \pm 24.31$ & $158.6 \pm 18.30$ & $<\mathbf{0 0 1}$ \\
\hline Blood loss (ml) & $151.0 \pm 38.75$ & $216.8 \pm 89.54$ & $\mathbf{0 . 0 0 2}$ \\
\hline Hospital stay (days) & $4.19 \pm 1.44$ & $6.21 \pm 2.42$ & $\mathbf{0 . 0 0 1}$ \\
\hline
\end{tabular}

Table III: ASD, Fusion and Complication Rates

\begin{tabular}{|c|c|c|c|}
\hline Parameters & Unilateral & Bilateral & $\mathbf{p}$ \\
\hline \multicolumn{4}{|l|}{ Complication } \\
\hline$(-)$ & $20(95.2)$ & $32(97.0)$ & \multirow{2}{*}{0.631} \\
\hline$(+)$ & $1(4.8)$ & $1(3.0)$ & \\
\hline \multicolumn{4}{|l|}{ Fusion } \\
\hline$(-)$ & $1(4.8)$ & $2(6.1)$ & \multirow{2}{*}{0.667} \\
\hline$(+)$ & $20(95.2)$ & 31 (93.9) & \\
\hline \multicolumn{4}{|l|}{ ASD } \\
\hline$(-)$ & $19(90.5)$ & $30(90.9)$ & \multirow{2}{*}{0.653} \\
\hline$(+)$ & $2(9.5)$ & $3(9.1)$ & \\
\hline
\end{tabular}

ASD: Adjacent segment disease. 
Table IV: VAS and ODI Scores

Time

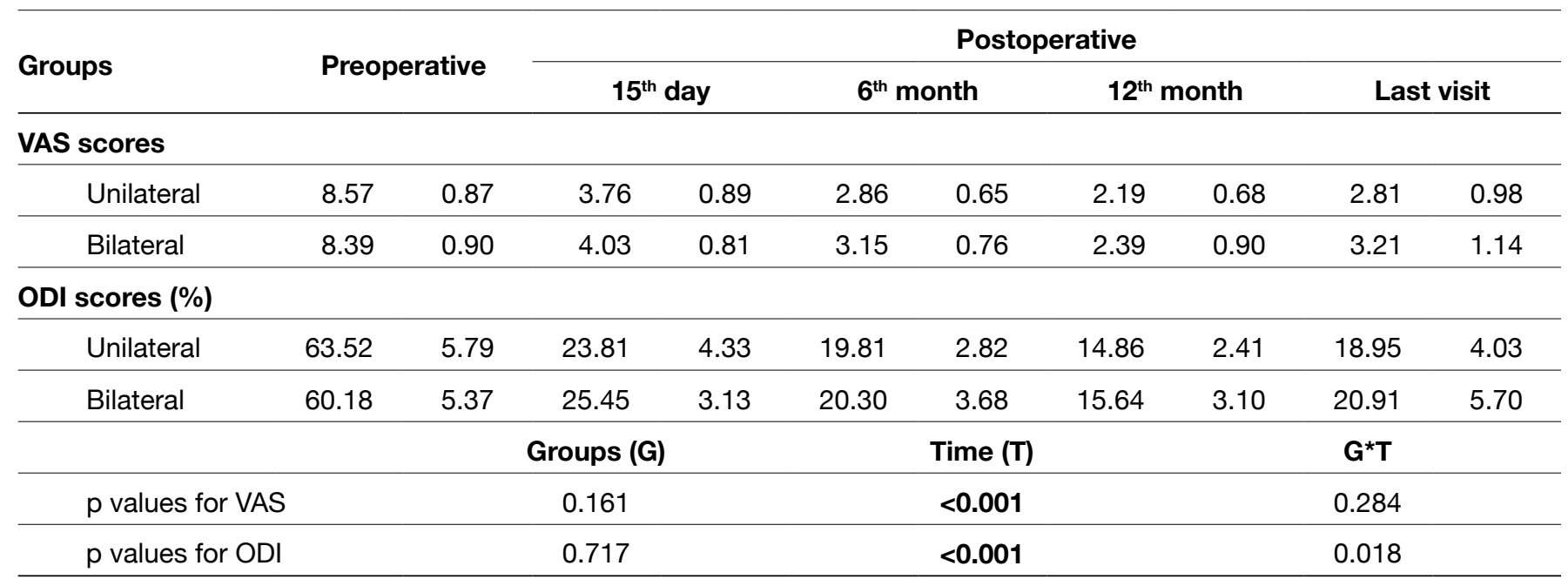

(24). Studies have shown that ASD develops in much shorter periods of time in cases involving instrumentation than those that do not $(25-26,8$ months) $(3,7,14,31)$. In a study conducted by $\mathrm{Kim}$ et al. with a 10-year follow-up, higher rates are reported in the bilateral PSF group (14). Likewise, Toyone, in his published study, reported less adjacent segment degeneration in the unilateral PSF group (37). There are also other studies available in the literature supporting the same view $(15,39)$. In our study, 2 patients in the unilateral group and 3 in the bilateral were diagnosed with adjacent segment degeneration. All these patients were followed up for more than 48 months and none of them was severe enough for reoperation. The patients that we include in this study are still followed-up and long-term results for ASD will be the subject of another study that we plan to do.

In addition to all the information stated above, some other drawbacks of bilateral screw fixation compared to unilateral screw fixation are also reported in the literature. One of the most important ones is the tissue damage caused by bilateral opening. Because of bilateral opening, tissue damage to occur at both sides will naturally prolong the healing process and cause more postoperative pain $(4,12,30)$.

In terms of operation time, it is identified that the group undergoing unilateral screw fixation had significantly shorter operation time, which is in line with the literature $(5,18,33,39)$. As well known, lumbar degenerative diseases are mostly seen as advanced age diseases. The gradual aging of the world population indicates that we will have to perform these operations on older patients. It is an inevitable fact that this old age population has in general many systemic diseases; just to name a few; hypertension, diabetes mellitus, rheumatic, or cardiovascular diseases etc. Therefore, under the light of this information, neural decompression and fusion to be practiced on these patients should be as minimally invasive and as short as possible. We will be facing them as parameters to affect morbidity and mortality of the patients. In our study, no additional morbidity or mortality was recorded in any of the patients.

Another drawback of bilateral pedicle screw fixation is that it causes more blood loss. In bilateral procedure, it is inevitable to have more blood loss during decompression of neural elements and TLIF procedure along with screwswith the opening of both sides. This is a clear-cut fact stated in all studies $(5,9,33,39,40)$. Similarly, when hospital stay is taken into account, it is another well accepted parameter in the published studies that patients undergoing unilateral pedicle screw fixation have significantly shorter hospital stay and go back to their routine lives in a much shorter period of time $(5,6,9,18,33,39,40)$. Likewise, in our study, in line with the literature, we reported significantly less blood loss and shorter hospital stay in the unilateral group.

Functional evaluation was done using preoperative and postoperative VAS and ODI scores. The results indicated significant clinical recovery when preoperative and postoperative scores were compared in both groups. These results are also compatible with the literature. As the follow-up periods get longer, however, a slight increase is observed in VAS and ODI scores in both groups. We think that as the follow-up period gets longer, the natural process of degeneration develops, and this increase can be the result of an ASD that has developed or may develop in future in all patients undergoing instrumented fusion. Within this framework, as mentioned before, we would like to highlight the need for longer follow-up.

Another advantage reported in the literature for unilateral pedicle screw fixation is the fact that it is inexpensive $(5,28,40,41)$. However, in the calculations, invoices issued by the hospitals are taken as basis including the cost of the materials used in the studies as well as the hospital stay. According to our point of view, these assessments are not appropriate and enough. The reason why is that it is already well known that fewer instruments are used in unilateral screw 
fixation and the hospital stay is shorter, and therefore, they will of course bring along a price advantage. But, in addition to that, the advantages of being able to have another surgical procedure as the operating room is used less, having no or less blood transfusion, having fewer complications and lower probability of infection caused by the unilateral procedure, together with not using, and therefore not spending money on medications as the patient has less pain, and earlier return of the patient to his work are not taken into account in these studies. According to us, cost-effectiveness is a subject that requires more detailed analysis and may be a topic of another study. Nonetheless, unilateral PSF group was found to be a cost-effective procedure in line with the literature being independent from the amount.

When it comes to complications, both patient groups were analyzed in terms of dural injury, screw malposition, screw failure, cage migration, infection and thromboembolism. Within this framework, no significant difference was found between the two groups. Yuan, Aoki and Liu reported higher rates of cage migration in their study for the unilateral PSF group $(2,18,24,41)$. In a great majority of the published series and in systematic reviews, no difference was found in terms of complications between the two groups $(23,41)$. In their study, Rivet et al. reported similar successful clinical results for both groups if the operations were performed by an experienced surgeon (29). As for our study, we similarly think that in addition to the safety of the surgical procedure, performance of all the operations by the same two experienced surgeons also played a role in our low rates of complications and in having clinical success that is compatible with the literature.

There are some limitations to our study. First of all, being a retrospective study per se is factor that is diminishing its value. Secondly, the relatively low number of patients in this study is another limitation. And last but not least, longer follow-up periods could have been more convenient in order to reach more meaningful results.

\section{CONCLUSION}

Unilateral pedicle screw fixation along with TLIF procedure is an appropriate, safe and effective option particularly in selected patients for fusion following neural decompression in the surgical treatment of lumbar degenerative diseases. However, we need prospective randomized studies with higher number of patients and longer follow-up periods for more reliable results.

\section{REFERENCES}

1. Ambati DV, Wright EK Jr, Lehman RA Jr, Kang DG, Wagner SC, Dmitriev AE: Bilateral pedicle screw fixation provides superior biomechanical stability intransforaminal lumbar interbody fusion: A finite element study. Spine J 15(8):1812-1822, 2015
2. Aoki Y, Yamagata M, Nakajima F, Ikeda Y, Shimizu K, Yoshihara M, Iwasaki J, Toyone T, Nakagawa K, Nakajima A, Takahashi $\mathrm{K}$, Ohtori S: Examining risk factors for posterior migration of fusion cages following transforaminal lumbar interbody fusion: A possible limitation of unilateral pedicle screw fixation. $J$ Neurosurg Spine 13(3):381-387, 2010

3. Aota Y, Kumano K, Hirabayashi S: Postfusion instability at the adjacent segments after rigid pedicle screw fixation for degenerative lumbar spinal disorders. J Spinal Disord 8(6): 464-473, 1995

4. Beringer WF, Mobasser JP: Unilateral pedicle screw instrumentation for minimally invasive transforaminal lumbar interbody fusion. Neurosurg Focus 20(3):E4, 2006

5. Chen C, Cao X, Zou L, Hao G, Zhou Z, Zhang G: Minimally invasive unilateral versus bilateral technique in performing single-segment pedicle screw fixation and lumbar interbody fusion. J Orthop Surg Res 10:112, 2015

6. Ding W, Chen Y, Liu H, Wang J, Zheng Z: Comparison of unilateral versus bilateral pedicle screw fixation in lumbar interbody fusion: A meta-analysis. Eur Spine J 23(2):395-403, 2014

7. Etebar S, Cahill DW: Risk factors for adjacent-segment failure following lumbar fixation with rigid instrumentation for degenerative instability. J Neurosurg 90 Suppl 2:163-169, 1999.

8. Fernández-Fairen $M$, Sala $P$, Ramírez $H$, Gil J: A prospective randomized study of unilateral versus bilateral instrumented posterolateral lumbar fusion in degenerative spondylolisthesis. Spine (Phila Pa 1976) 32(4):395-401, 2007

9. Goel VK, Lim TH, Gwon J, Chen JY, Winterbottom JM, Park JB, Weinstein JN, Ahn JY: Effects of rigidity of an internal fixation device. A comprehensive biomechanical investigation. Spine (Phila Pa 1976) 16 Suppl 3: S155-161, 1991

10. Harms JG, Rollinger H: Die operative Behandlung der Spondylolisthese durch dorsale Auf richtungund ventrale Verblockung. Z Orthop 120: 343-347,1982 (In German)

11. Harris BM, Hilibrand AS, Savas PE, Pellegrino A, Vaccaro AR, Siegler S, Albert TJ: Transforaminal lumbar interbody fusion: The effect of various instrumentation techniques on the flexibility of the lumbar spine. Spine (Phila Pa 1976) 29(4): E65-70, 2004

12. Hu XQ, Wu XL, Xu C, Zheng XH, Jin YL, Wu LJ, Wang XY, Xu HZ, Tian NF: A systematic review and meta-analysis of unilateral versus bilateral pedicle screw fixation in transforaminal lumbar interbody fusion. PLoS One 9(1):e87501, 2014

13. Kasai Y, Inaba T, Kato T, Matsumura Y, Akeda K, Uchida A: Biomechanical study of the lumbar spine using a unilateral pedicle screw fixation system. J Clin Neurosci 17(3):364-367, 2010

14. Kim TH, Lee BH, Moon SH, Lee SH, Lee HM: Comparison of adjacent segment degeneration after successful posterolateral fusion with unilateral or bilateral pedicle screw instrumentation: A minimum 10-year follow-up. Spine J 13(10):1208-1216, 2013 
15. Korovessis P, Papazisis Z, Koureas G, Lambiris E: Rigid, semirigid versus dynamic instrumentation for degenerative lumbar spinal stenosis: A correlative radiological and clinical analysis of short-term results. Spine (Phila Pa 1976) 29(7): 735-742, 2004

16. Kotil K: Mini-open (less invasive) TLIF procedure with unilateral pedicle screw fixation. WSCJ 5:104-109, 2014

17. Lauber S, Schulte TL, Liljenqvist U, Halm H, Hackenberg $\mathrm{L}$ : Clinical and radiologic 2-4-year results of transforaminal lumbar interbody fusion in degenerative and isthmic spondylolisthesis grades 1 and 2. Spine (Phila Pa 1976) 31(15):1693-1698, 2006

18. Li X, Lv C, Yan T: Unilateral versus bilateral pedicle screw fixation for degenerative lumbar diseases: A meta-analysis of 10 randomized controlled trials. Med Sci Monit 21:782-790, 2015

19. Li Z, Liu F, Liu S, Chen Z, Jiang C, Feng Z, Jiang X: Miniopen transforaminal lumbar interbody fusion with unilateral fixation: A comparison between ipsilateral and contralateral reherniation. Biomed Res Int 2016:7261027, 2016

20. Lin B, Xu Y, He Y, Zhang B, Lin Q, He M: Minimally invasive unilateral pedicle screw fixation and lumbar interbody fusion for the treatment of lumbar degenerative disease. Orthopedics 36(8): e1071-1076, 2013

21. Liu F, Feng Z, Zhou X, Liang Y, Jiang C, Li X, Li Z, Jiang $X$, Dong J: Unilateral versus bilateral pedicle screw fixation in transforaminal lumbar interbody fusion: A monocentric study of 215 patients with a minimum of 4-year follow-up. Clin Spine Surg 30(6):E776-E783, 2017

22. Mao L, Chen GD, Xu XM, Guo Z, Yang HL: Comparison of lumbar interbody fusion performed with unilateral or bilateral pedicle screw. Orthopedics 36(4):e489-493, 2013

23. Molinari R, Saleh A, Molinari R Jr, Hermsmeyer J, Dettori J: Unilateral versus bilateral instrumentation in spinal surgery: $A$ systematic review. Global Spine J 5:185-194, 2015

24. Park P, Garton HJ, Gala VC, Hoff JT, McGillicuddy JE: Adjacent segment disease after lumbar or lumbosacral fusion: Review of the literature. Spine (Phila Pa 1976) 29(17):1938-1944, 2004

25. Phan K, Leung V, Scherman D, Tan A, Rao P, Mobbs R: Bilateral versus unilateral instrumentation in spinal surgery: Systematic review and trial sequential analysis of prospective studies. J Clin Neurosci 30:15-23, 2016

26. Potter BK, Freedman BA, Verwiebe EG, Hall JM, Polly DW Jr, Kuklo TR: Transforaminal lumbar interbody fusion: Clinical and radiographic results and complications in 100 consecutive patients. J Spinal Disord Tech 18(4):337-346, 2005

27. Quante M, Kesten H, Richter A, Halm H: Transforaminal lumbar interbody fusion for the treatment of degenerative spondylolisthesis. Orthopade 41(2):153-162, 2012 (In German)

28. Rihn JA: Commentary: Is bilateral pedicle screw fixation necessary when performing a transforaminal lumbar interbody fusion? An analysis of clinical outcomes, radiographic outcomes, and cost. Spine J 12(3):216-217, 2012
29. Rivet DJ, Jeck D, Brennan J, Epstein A, Lauryssen C: Clinical outcomes and complications associated with pedicle screw fixation-augmented lumbar interbody fusion. J Neurosurg Spine 1(3): 261-266, 2004

30. Salehi SA, Tawk R, Ganju A, LaMarca F, Liu JC, Ondra SL: Transforaminal lumbar interbody fusion: Surgical technique and results in 24 patients. Neurosurgery 54(2):368-374; discussion 374, 2004

31. Schlegel JD, Smith JA, Schleusener RL: Lumbar motion segment pathology adjacent to thoracolumbar, lumbar, and lumbosacral fusions. Spine (Phila Pa 1976) 21(8):970-981, 1996

32. Shen X, Wang L, Zhang H, Gu X, Gu G, He S: Radiographic analysis of one-level minimally invasive transforaminal lumbar interbody fusion (MI-TLIF) with unilateral pedicle screw fixation for lumbar degenerative diseases. Clin Spine Surg 29(1):E1-8, 2016

33. Shen X, Zhang H, Gu X, Gu G, Zhou X, He S: Unilateral versus bilateral pedicle screw instrumentation for single-level minimally invasive transforaminal lumbar interbody fusion. $J$ Clin Neurosci 21(9):1612-1616, 2014

34. Shono Y, Kaneda K, Abumi K, McAfee PC, Cunningham BW: Stability of posterior spinal instrumentation and its effects on adjacent motion segments in the lumbosacral spine. Spine (Phila Pa 1976) 23(14):1550-1558, 1998

35. Slucky AV, Brodke DS, Bachus KN, Droge JA, Braun JT: Less invasive posterior fixation method following transforaminal lumbar interbody fusion: A biomechanical analysis. Spine $\mathrm{J}$ 6(1):78-85, 2006

36. Suk KS, Lee HM, Kim NH, Ha JW: Unilateral versus bilateral pedicle screw fixation in lumbar spinal fusion. Spine (Phila $\mathrm{Pa}$ 1976) 25(14):1843-1847, 2000

37. Toyone T, Ozawa T, Kamikawa K, Watanabe A, Matsuki K, Yamashita T, Shiboi R, Takeuchi M, Wada Y, Inada K, Aoki Y, Inoue G, Ohtori S, Tanaka T: Subsequent vertebral fractures following spinal fusion surgery for degenerative lumbar disease: A mean ten-year follow-up. Spine (Phila Pa 1976) 35(21):1915-1918, 2010

38. Xie Y, Ma H, Li H, Ding W, Zhao C, Zhang P, Zhao J: Comparative study of unilateral and bilateral pedicle screw fixation in posterior lumbar interbody fusion. Orthopedics 35(10):e1517-1523, 2012

39. Xue H, Tu Y, Cai M: Comparison of unilateral versus bilateral instrumented transforaminal lumbar interbody fusion in degenerative lumbar diseases. Spine J 12(3):209-215, 2012

40. Yang SD, Chen Q, Ding WY, Zhao JQ, Zhang YZ, Shen Y, Yang DL: Unilateral pedicle screw fixation with bone graft vs. bilateral pedicle screw fixation with bone graft or cage: $A$ comparative study. Med Sci Monit 22:890-897, 2016

41. Yuan $\mathrm{C}$, Chen $\mathrm{K}$, Zhang $\mathrm{H}$, Zhang $\mathrm{H}$, He S: Unilateral versus bilateral pedicle screw fixation in lumbar interbody fusion: $A$ meta-analysis of complication and fusion rate. Clin Neurol Neurosurg 117: 28-32, 2014 
42. Yucesoy K, Yuksel KZ, Baek S, Sonntag VK, Crawford NR: Biomechanics of unilateral compared with bilateral lumbar pedicle screw fixation for stabilization of unilateral vertebral disease. J Neurosurg Spine 8(1):44-51, 2008

43. Zhang $K$, Sun W, Zhao CQ, Li H, Ding W, Xie YZ, Sun XJ, Zhao J: Unilateral versus bilateral instrumented transforaminal lumbar interbody fusion in two-level degenerative lumbar disorders: A prospective randomised study. Int Orthop 38(1): 111-116, 2014
44. Zhao CQ, Ding W, Zhang K, Zhao J: Transforaminal lumbar interbody fusion using one diagonal fusion cage with unilateral pedicle screw fixation for treatment of massive lumbar disc herniation. Indian J Orthop 50(5): 473-478, 2016

45. Zhao J, Zhang F, Chen X, Yao Y: Posterior interbody fusion using a diagonal cage with unilateral transpedicular screw fixation for lumbar stenosis. J Clin Neurosci 18(3):324-328, 2011 